\title{
Low-dose cyclophosphamide-induced hyponatremia in primary breast cancer
}

\author{
Yasutaka Tono $^{1 \#}$, Toshiro Mizuno ${ }^{1 * *}$, Hiroyasu Oda ${ }^{1}$, Mikiya Ishihara $^{1}$, Kanako Saito ${ }^{1}$, Yoshiki Yamashita ${ }^{1}$ and Kazunori Nakase ${ }^{2}$ \\ ${ }^{1}$ Department of Medical Oncology, Mie University Hospital, 2-174, Edobashi, Tsu, Mie 514-8507, Japan \\ ${ }^{2}$ Cancer Center, Mie University Hospital, 2-174, Edobashi, Tsu, Mie 514-8507, Japan \\ ${ }^{\#}$ Contributed equally to this work
}

\begin{abstract}
Cyclophosphamide (CPA) is an alkylating agent widely used in antineoplastic therapies. Hyponatremia is a common side effect of high-dose CPA treatment. However, there are few reports about hyponatremia induced by low-dose CPA. We investigated its incidence, clinical course, risk factors in patients with breast cancer. Ninety-seven females with primary breast cancer receiving CPA $\left(600 \mathrm{mg} / \mathrm{m}^{2}\right)$-containing adjuvant chemotherapy were prospectively studied for 2 years at our hospital. Hyponatremia was defined as a serum sodium level $<135 \mathrm{mEq} / \mathrm{L}$. The observed incidence of hyponatremia was $18.6 \%$, but severe hyponatremia $(<125 \mathrm{mEq} / \mathrm{L})$ was not seen in any patients. In most cases, the patients' serum sodium levels returned to normal within around 48 hours. In univariate analysis, age $(P=0.008)$, serum sodium level at baseline $(P=0.001)$, expression of progesterone receptor $(P=0.030)$, anthracycline and CPA treatment $(P=0.015)$, and use of aprepitant $(P=0.032)$ were significantly correlated with hyponatremia. Multivariate analysis revealed that baseline lower serum sodium level $(P=0.051)$ and younger age $(P=0.053)$ could be independent possible risk factors of hyponatremia. Our results indicate that low-dose CPA-induced hyponatremia was not rare in breast cancer patients, but it recovered without specific management. Age and pretreatment serum sodium level tended to be independently associated with the occurrence of hyponatremia.
\end{abstract}

\section{Introduction}

Hyponatremia is the most common electrolyte disturbance seen in patients receiving anticancer drugs. Several cytotoxic agents, including carboplatin, cisplatin, vincristine, and vinblastine, have been found to cause hyponatremia. Recently, clinically significant hyponatremia has been reported in cancer patients treated with moleculartargeted therapies [1]. Moreover, several studies have suggested that hyponatremia is a poor prognostic factor among cancer patients [2,3].

Hyponatremia has been also reported to be a major complication among cases in which high doses of cyclophosphamide (CPA) were used as part of a conditioning regimen for bone marrow transplants [4-7]. However, there is little clinical data about the occurrence of hyponatremia during the routine use of low-dose CPA to treat breast cancer. A retrospective study reported that all of the patients that developed the condition recovered without any sequelae [8].

We recently encountered a case in which severe low-dose CPAinduced hyponatremia occurred in a patient with breast cancer. We speculated that the use of aprepitant, a neurokinin-1 receptor antagonist, to prevent chemotherapy-induced nausea and vomiting (CINV) was associated with hyponatremia [9]. From the viewpoint of drug-drug interactions, it is possible that advances in supportive care may increase the risk of hyponatremia in patients receiving cancer treatment.

We investigated the incidence, clinical course, and risk factors of hyponatremia in primary breast cancer patients that received adjuvant chemotherapy involving low-dose CPA.

\section{Materials and methods}

We carried out a prospective observational study of patients with primary breast cancer who were admitted to our hospital between
December 2010 and October 2012. This study was conducted in accordance with the Declaration of Helsinki and was approved by our institutional review board. Females with primary breast cancer who were candidates for adjuvant chemotherapy involving CPA $(600 \mathrm{mg} /$ $\mathrm{m}^{2}$ ) were eligible for this study. In all patients, hypotonic electrolyte infusions were equally used for prophylactic hydration following CPA treatment. The inclusion criteria included an age of $<65$ years old; an Eastern Cooperative Oncology Group performance status of 0 to 1; adequate renal function (an estimated glomerular filtration rate of $<60$ $\mathrm{mL} / \mathrm{min} / 1.73 \mathrm{~m}^{2}$ ); and the absence of an electrolyte imbalance, diabetes mellitus, or dyslipidemia.

We assessed the differences between the serum sodium concentrations observed at the start of the first cycle and after 24 hours. Hyponatremia was defined as a serum sodium level of $<135 \mathrm{mEq} / \mathrm{L}$ [8], and was considered to be severe when the patient's serum sodium level was $<125 \mathrm{mEq} / \mathrm{L}$. Patients that were diagnosed with hyponatremia were closely monitored, and their electrolyte levels were examined every 24 hours until their serum sodium concentrations recovered to within the normal range (Figure 1).

\section{Statistical analysis}

To identify risk factors potentially associated with the occurrence of hyponatremia, each factor was compared by Fisher's exact test

*Correspondence to: Toshiro Mizuno, Department of Medical Oncology, Mie University Hospital, 2-174, Edobashi, Tsu, Mie 514-8507, Japan, Tel: +81-59231-5296; Fax: +81-59-231-5348; E-mail: tomizuno@clin.medic.mie-u.ac.jp

Key words: hyponatremia, low-dose cyclophosphamide, breast cancer

Received: September 28, 2020; Accepted: October 08, 2020; Published: October 15,2020 


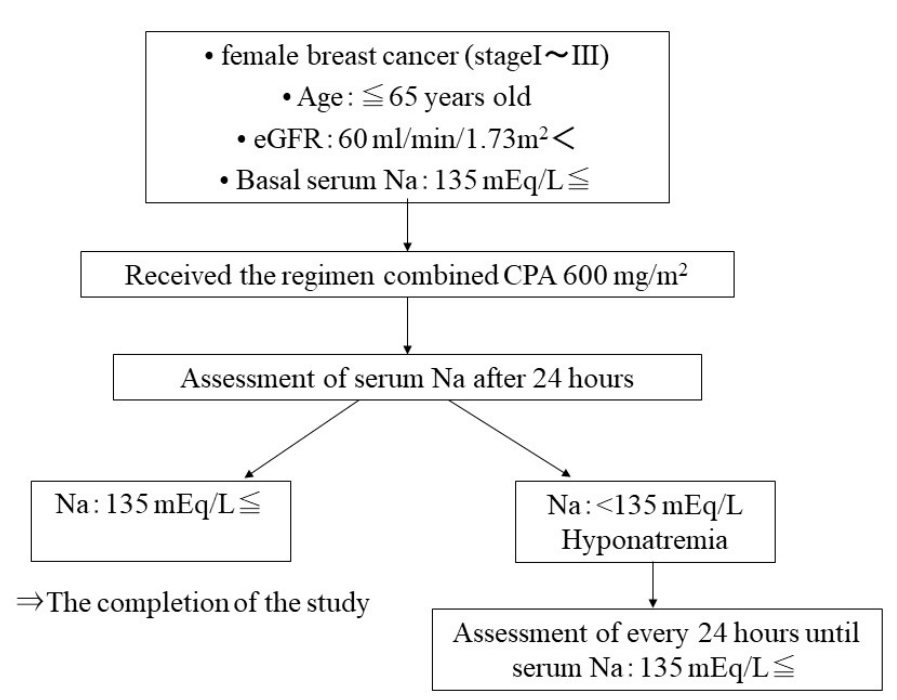

Figure 1. Flow diagram of this study

and Mann-Whitney U-test. The factors were age, pathological stage, estrogen receptor (ER) status, progesterone receptor (PgR) status, human epidermal growth factor receptor type 2 (HER2) status, serum sodium concentrations at baseline, chemotherapy regimen, and antiemetics. The risk factors were also evaluated in multivariable analysis with the logistic regression model [9]. The 95\% confidence interval (CI) for the risk ratio was calculated for the independent prognostic factors. All analyses were conducted with EZR (version 1.50; Saitama Medical Center, Jichi Medical University, Saitama, Japan) [10]. Statistical significance was defined as a p-value of $<0.05$.

\section{Results}

\section{Base line characteristics}

In total, 97 patients were enrolled between December 2010 and October 2012. The patients' baseline characteristics are shown in Table 1. Their median age was 51.3 years (range: 31 to 65 ), and 32,41 , and 24 patients had stage I, stage II, and stage III disease, respectively. Tumors were ER-positive in 72 patients and negative in 25. Tumors were PgR-positive in 61 patients and negative in 36 . Tumors were HER2-positive in 29 patients and negative in 68. Of the 97 patients, 62 received anthracycline-containing regimens (doxorubicin and CPA [AC]: 56 patients, epirubicin and CPA [EC]: 6 patients). The remaining 35 patients were treated with docetaxel and CPA (TC). The patients' pretreatment serum sodium concentration $($ mean \pm SD) was $139.9 \pm 1.9$ $\mathrm{mEq} / \mathrm{L}$.

\section{Incidence of hyponatremia}

Low-dose CPA-induced hyponatremia was found in 18 of the 97 patients (18.6\%) (Table 2). The median age of these 18 patients was 40 years (range: 31 to 62 ). Sixteen were treated with AC, while the remaining 2 were given TC. Serum sodium concentration (mean \pm SD) taken 24 hours after the CPA therapy in these 18 patients was $138.6 \pm$ $1.7 \mathrm{mEq} / \mathrm{L}$, and none developed severe hyponatremia. Among them, 14 patients had their serum sodium concentrations monitored for more than 48 hours. In most cases, the patients' serum sodium levels returned to normal within around 48 hours, but protracted (until day 5) hyponatremia was seen in 1 patient (Patient 11).

\section{Clinicopathologic analysis of risk factors of hyponatremia}

Comparison of clinical characteristics between patients with and without CPA-induced hyponatremia is shown in Table 3. Patients with hyponatremia were significantly younger than those without hyponatremia ( $45.2 \pm 11.0$ vs. $52.6 \pm 8.4$ years of age, $P=0.008$ ). Baseline serum sodium levels in patients with hyponatremia were significantly lower than those in patients without hyponatremia (138.6 \pm 1.7 vs. $140.2 \pm 1.9 \mathrm{mEq} / \mathrm{L}, P=0.001) . \mathrm{PgR}$ was more commonly expressed in patients without hyponatremia than in those with hyponatremia [54 patients $(68.4 \%)$ vs. 7 patients (38.9\%), $P=0.030$ ]. Anthracyclinecontaining regimens were more frequently associated with patients with hyponatremia than those without hyponatremia [16 patients $(88.9 \%)$ vs. 46 patients $(58.2 \%), P=0.015)]$. All patients were given a serotonin antagonist and dexamethasone to prevent CINV. As for aprepitant, its use was more closely related to patients with hyponatremia than those without hyponatremia [ 15 patients $(83.3 \%)$ vs. 43 patients $(54.4 \%)$, $P=0.032]$.

Table 1. Patient characteristics at baseline

\begin{tabular}{|l|c|}
\hline $\begin{array}{l}\text { Age, years } \\
\text { Median (Range) }\end{array}$ & $51.28(31-65)$ \\
\hline Stage at registration & $32 / 41 / 24$ \\
I/II/III & \\
\hline Hormone receptor status & $72 / 25$ \\
ER $+/$ - & $61 / 36$ \\
PgR +/- & \\
\hline HER2 status & $29 / 68$ \\
HER2 +/- & \\
\hline Chemotherapy regimen & $56 / 6$ \\
AC/EC & 35 \\
TC & 97 \\
\hline Antiemetics & 97 \\
Dexamethazone & 58 \\
Granisetron & $139.9 \pm 1.99 \mathrm{mEq} / \mathrm{L}$ \\
Aprepitant & \\
\hline Basal serum sodium levels & \\
\hline
\end{tabular}

ER: estrogen receptor; PgR: Progesterone receptor; HER2: Human epidermal growth factor receptor type 2; AC: Doxorubicin and cyclophosphamide; EC: Epirubicin and cyclophosphamide; TC: Docetaxel and cyclophosphamide

Table 2. Cases of hyponatremia

\begin{tabular}{|c|c|c|c|c|c|c|}
\hline Patient & Age & Stage & Regimen & Basal Na & $\mathbf{2 4}$ hrs & $\mathbf{4 8}$ hrs \\
\hline 1 & 47 & IIA & AC & 139 & 130 & 137 \\
\hline 2 & 62 & I & AC & 141 & 134 & 139 \\
\hline 3 & 53 & IIB & AC & 140 & 129 & 141 \\
\hline 4 & 37 & IIIA & AC & 140 & 131 & 135 \\
\hline 5 & 38 & IIB & AC & 138 & 133 & 137 \\
\hline 6 & 58 & I & AC & 140 & 130 & 135 \\
\hline 7 & 31 & IIA & AC & 136 & 133 & 136 \\
\hline 8 & 36 & I & AC & 138 & 130 & - \\
\hline 9 & 41 & IIB & AC & 140 & 132 & 139 \\
\hline 10 & 60 & I & AC & 140 & 132 & 139 \\
\hline 11 & 35 & IIIC & AC & 139 & 130 & 133 \\
\hline 12 & 37 & IIIC & AC & 138 & 134 & 135 \\
\hline 13 & 56 & IIIA & AC & 139 & 131 & 134 \\
\hline 14 & 33 & IIB & AC & 140 & 133 & - \\
\hline 15 & 47 & IIA & AC & 135 & 134 & - \\
\hline 16 & 38 & IIIC & AC & 137 & 133 & 137 \\
\hline 17 & 65 & IIB & TC & 138 & 132 & 140 \\
\hline 18 & 39 & IIB & TC & 136 & 133 & - \\
\hline
\end{tabular}

Basal Na, serum sodium levels at baseline

24 hrs: 24 hours; 48 hrs: 48 hours

AC: doxorubicin and cyclophosphamide; TC: docetaxel and cyclophosphamide 
The expression of ER and HER2, and pathological stage were not significantly different between patient with and without hyponatremia.

\section{Multivariate analysis}

We carried out multivariate analysis using the factors of age, serum sodium concentrations at baseline, expression of $\mathrm{PgR}$, use of anthracycline-based regimen, and use of aprepitant (Table 4). No significant association was found between these factors and the development of hyponatremia; however, patients who had lower serum sodium concentrations at baseline (OR: 0.70, 95\% CI: 0.49-1.00, $p=0.051$ ) and younger age (OR: $0.93,95 \%$ CI: $0.87-1.00, p=0.053)$ tended to be independently associated with the occurrence of hyponatremia.

\section{Discussion}

We prospectively investigated the incidence, clinical course, and risk factors of low-dose CPA-associated hyponatremia in primary breast cancer patients. Our study indicated that its incidence was $18.6 \%$ that was slightly higher than Lee et al. findings [8]. This may be because we evaluated the occurrence of hyponatremia only in the first course of chemotherapy. In this study, no severe cases of hyponatremia (< $125 \mathrm{mEq} / \mathrm{L}$ ) was found, and patients' clinical courses were consistent with those described in a previous study [8]. Our results suggested that, in primary breast cancer patients with a good performance status, no special management is needed to prevent the development of hyponatremia in clinical practice. However, given that hyponatremia during treatment was not a rare event and there have been reports of severe cases $[9,11-16]$, it was meaningful to identify risk factors of hyponatremia. So far, no risk factor has been established for the development of low-dose CPA-induced hyponatremia.

Table 3. Comparison between patients with and without hyponatremia

\begin{tabular}{|c|c|c|c|}
\hline & $\begin{array}{c}\text { Hyponatremia (-) } \\
\mathbf{N = 7 9}\end{array}$ & $\begin{array}{c}\text { Hyponatremia }(+) \\
\mathbf{N}=\mathbf{1 8}\end{array}$ & p-value \\
\hline Age & & & \\
Mean \pm SD & $52.6 \pm 8.4$ & $45.2 \pm 11.0$ & 0.008 \\
\hline Basal Na & & & \\
Mean \pm SD & $140.2 \pm 1.9$ & $138.6 \pm 1.7$ & 0.001 \\
\hline ER +/- & $58 / 21$ & $14 / 4$ & 1 \\
\hline PgR +/- & $54 / 25$ & $7 / 11$ & 0.030 \\
\hline HER2 +/- & $23 / 56$ & $6 / 12$ & 0.778 \\
\hline Stage & & & \\
I & 28 & 4 & 0.568 \\
II & 32 & 5 & \\
III & 19 & 16 & 0.015 \\
\hline Regimen & 46 & 2 & 0.032 \\
\hline AC/EC & 33 & $15 / 3$ & \\
TC & $43 / 36$ & & \\
\hline Aprepitant & & & \\
\hline
\end{tabular}

Basal Na, serum sodium levels at baseline

ER: estrogen receptor; PgR, progesterone receptor; HER2, human epidermal growth factor receptor type 2 ;

AC: doxorubicin and cyclophosphamide; EC: epirubicin and cyclophosphamide: TC, docetaxel and cyclophosphamide

Table 4. Multivariate analysis for hyponatremia

\begin{tabular}{|c|c|c|c|}
\hline Factor & Odds Ratio & $\mathbf{9 5 \%}$ CI & p-value \\
\hline Basal Na & 0.70 & $0.49-1.00$ & 0.051 \\
\hline Age & 0.93 & $0.87-1.00$ & 0.053 \\
\hline Anthracyclines & 0.13 & $0.01-2.84$ & 0.194 \\
\hline PgR & 0.29 & $0.08-1.12$ & 0.073 \\
\hline Aprepitant & 0.48 & $0.03-8.59$ & 0.620 \\
\hline
\end{tabular}

95\% CI: 95\% confidence interval

Basal Na, serum sodium levels at baseline

PgR: progesterone receptor
Initially, we focused on the use of aprepitant as a risk factor because we previously experienced this drug possibly associated severe hyponatremia in a patient with breast cancer [9]. Although univariate analysis revealed that the use of aprepitant was closely related to the occurrence of hyponatremia, it was not extracted as an independent risk factor by multivariate analysis. On the other hand, lower serum sodium level at baseline and younger age were shown to be independent possible risk factors. A retrospective study of risk factors of cisplatinrelated hyponatremia also reported that lower baseline serum sodium concentration $(<138 \mathrm{mEq} / \mathrm{L})$ was a risk factor for severe hyponatremia [17]. Our observation indicated that patients who had pretreatment lower sodium concentration may be likely to result in hyponatremia $(<135 \mathrm{mEq} / \mathrm{L})$ even with small decline of its level after hypotonic electrolyte infusion following CPA administration. It is unclear why younger age remained a candidate risk factor for hyponatremia. It may be due to the influence of nausea and vomiting, which stimulate antidiuretic hormone $(\mathrm{ADH})$ production. In our data, an additional retrospective analysis showed emesis (grade $2 \geq$ by CTCAE ver. 5) occurred frequently in the hyponatremia group (data not shown). Younger age was also described to be one of risk factors that enhanced the incidence of CINV $[18,19]$.

The mechanism of hyponatremia by CPA have not been fully understood. As one of its mechanism, the syndrome of inappropriate $\mathrm{ADH}$ secretion has been proposed in cases of severe hyponatremia receiving CPA [20,21]. However, other studies have demonstrated that monitored serum $\mathrm{ADH}$ levels have not altered in patients during CPA treatment [22]. In addition, several investigators suggested a direct antidiuretic effect of CPA or its metabolites on renal collecting tubules and/or ADH-like activity of CPA metabolites [6,23]. Since our study lacked evaluations of pharmacokinetics of CPA and other factors including $\mathrm{ADH}$ that can affect hyponatremia, further investigations are required to clarify the precise mechanism of the development of hyponatremia related to CPA.

\section{Conclusion}

In conclusion, low-dose CPA-induced hyponatremia was not rare in breast cancer patients, but it recovered without specific management. Age and pretreatment serum sodium level were considered to be independent possible risk factors of hyponatremia. However, the small sample size of this single-center study may have led to selection bias. Thus, additional large-scale studies are required to confirm our observation and to verify the pathological significance of low-dose $\mathrm{CPA}$-induced hyponatremia in patients with breast cancer.

\section{Acknowledgements}

The authors thank all medical staff at Mie University Hospital who were involved in this study.

\section{Conflicts of interest}

The authors declare that they have no conflicts of interest.

\section{Funding statements}

This research did not receive any specific grant from funding agencies in the public, commercial, or not-for-profit sectors.

\section{References}

1. Rossana B, Matteo S, Silvia R, Emilia N, Alessia S, et al. (2016) Risk of hyponatraemia in cancer patients treated with targeted therapies: A Systematic review and metaanalysis of clinical trials. PLoS One 11: e0152079. [Crossref] 
2. Fabio ABS, Wanling X, Frede D, Monica S, David FM, et al. (2014) The impact of low serum sodium on treatment outcome of targeted therapy in metastatic renal cell carcinoma: Results from the international metastatic renal cell cancer database consortium. Eur Urol 65: 723-730. [Crossref]

3. Doshi SM, Shah P, Lei X, Lahoti A, Salahudeen AK (2012) Hyponatremia in hospitalized cancer patients and its impact on clinical outcomes. Am J kidney Dis 59 222-228.

4. DeFronzo RA, Braine H, Colvin M, Davis PJ (1973) Water intoxication in man after cyclophosphamide therapy. Time course and relation to drug activation. Ann Intern Med 78: 861-869. [Crossref]

5. Steele TH, Serpick AA, Block JB (1973) Antidiuretic response to cyclophosphamide in man. J Pharmacol Exp ther 185: 245-253. [Crossref]

6. DeFronzo RA, Colvin OM, Braine H, Roberson GL, Davis PJ (1974) Proceedings: Cyclophosphamide and the kidney. Cancer 33: 483-491.

7. Harlow PJ, DeClerck YA, Shore NA, Ortega JA, Carranza A, et al. (1979) A fatal case of inappropriate $\mathrm{ADH}$ secretion induced by cyclophosphamide therapy. Cancer 44 896-898. [Crossref]

8. Young-Chul L, Joon-Sung P, Chang Hwa L, Sang-Cheol B, In-Soon K, et al. (2010) Hyponatraemia induced by low-dose intravenous pulse cyclophosphamide. Nephrol Dial Transplant 25: 1520-1524.

9. Yasutaka T, Toshiro M, Kanako S, Satoshi T, Yoshiki Y, et al. (2012) Correlation between low-dose cyclophosphamide-induced hyponatraemia and the use of aprepitant. J Clin Oncol 30: e19546-e19546.

10. Kanda Y (2013) Investigation of the freely available easy-to-use software 'EZR' for medical statistics. Bone Marrow Transplant 48: 452-458. [Crossref]

11. Bruining DM, van Roon EN, de Graaf H, Hoogendoorn M (2011) Cyclophosphamideinduced symptomatic hyponatraemia. Neth J Med 69: 192-195.

12. Seong-Bae H, Hye-Yoon L, Hoon-Yub K, Eun-Sook L, Jeoung-Won B (2011) Lifethreatening acute hyponatremia with generalized seizure induced by low-dose cyclophosphamide in a patient with breast cancer. J Breast Cancer 14: 345-348. [Crossref]
13. Geng C, Tang P, Zhang Y, Gao W (2014) Hyponatremia induced by lowdose cyclophosphamide in two patients with breast cancer. Breast $J$ 20: 442-443. [Crossref]

14. Baker M, Markman M, Niu J (2014) Cyclophosphamide-induced severe acute hyponatremic encephalopathy in patients with breast cancer: Report of two cases. Case Rep Oncol 7: 550-554. [Crossref]

15. Elazzazy S, Mohamed AE, Gulied A (2014) Cyclophosphamide-induced symptomatic hyponatremia, a rare but severe side effect: A case report. Onco Targets Ther 30: 16411645.

16. Katherine Clifton, Chad Barnett, Ashley Martinez (2018) Two case reports of severe hyponatremia following cyclophosphamide infusion in breast cancer patients. Breast $J$ 24: 691-692. [Crossref]

17. Hatakeyama S, Shida T, Yamaguchi H (2019) Risk factors for severe hyponatremia related to cisplatin: A retrospective case-control study. Biol Pharm Bull 42: 1891-1897. [Crossref]

18. Christopher MB, Mark C, George D, Anil J, Scott Y, et al. (2007) Chemotherapyinduced nausea and vomiting in breast cancer patients: A prospective observational study. J Support Oncol 5: 374-380. [Crossref]

19. Minako Nawa N, Ryo K, Akio S, Chiemi H, Rie M, et al. (2018) Control of nausea and vomiting in patients receiving anthracycline/cyclophosphamide chemotherapy for breast cancer. Anticancer Res 38: 877-884.

20. Moses AM, Miller M (1974) Drug-induced dilutional hyponatremia. N Engl J Med 291 1234-1239. [Crossref]

21. Harlow PJ, DeClerck YK, Shore NA, Ortega JA, Carranza A, et al. (1979) A fatal case of inappropriate ADH secretion induced by cyclophosphamide therapy. Cancer 44: 896-898. [Crossref]

22. Bressler RB, Huston DP (1985) Water intoxication following moderate dose intravenous cyclophosphamide. Arch Intern Med 145: 548-549. [Crossref]

23. Campbell DM, Atkinson A, Gillis D, Sochett EB (2000) Cyclophosphamide and water retention: Mechanism revisited. J Pediatr Endocrinol Metab 13: 673-675. [Crossref]

Copyright: (C2020 Tono Y. This is an open-access article distributed under the terms of the Creative Commons Attribution License, which permits unrestricted use, distribution, and reproduction in any medium, provided the original author and source are credited. 